\title{
Preoperative Assessment of TERT Promoter Mutation on Thyroid Core Needle Biopsies Supports Diagnosis of Malignancy and Addresses Surgical Strategy
}

\author{
Authors \\ A. Crescenzi ${ }^{1}$, P. Trimboli ${ }^{2}$, D. Cicciarella Modica ${ }^{3}$, C. Taffon ${ }^{1}$, L. Guidobaldi ${ }^{3}$, S. Taccogna ${ }^{4}$, A. Rainer ${ }^{5}$, \\ M. Trombetta ${ }^{5}$, E. Papini ${ }^{6}$, G. Zelano \\ Affiliations \\ Affiliation addresses are listed at the end of the article
}

Key words
thyroid
cancer
TERT
core needle biopsy (CNB)

received 07.01 .2015

accepted 12.03.2015

\section{Bibliography}

DOI http://dx.doi.org/

10.1055/s-0035-1548873

Published online:

May 7, 2015

Horm Metab Res 2016;

48: 157-162

(c) Georg Thieme Verlag KG

Stuttgart · New York

ISSN 0018-5043

Correspondence

A. Crescenzi, MD

Pathology Unit

Campus Bio-Medico University Hospital

Via Alvaro del Portillo 200

00128 Rome

Italy

Tel.: + 39/06/225411 106

Fax: + 39/06/225411928

a.crescenzi@unicampus.it

\section{Abstract}

$\nabla$

In the last decade, several molecular markers have been proposed to improve the diagnosis of thyroid nodules. Among these, mutations in the telomerase reverse transcriptase (TERT) promoter have been correlated to malignant tumors, characterized by highest recurrence and decreased patients' survival. This suggests an important role of TERT mutational analysis in the clinical diagnosis and management of thyroid cancer patients. The aim of the study was to demonstrate the adequacy of core needle biopsy (CNB) for the preoperative assessment of TERT mutational status, to reach a more accurate definition of malignancy and a more appropriate surgical planning. Indeed, CNB is gaining momentum for improving diagnosis of thyroid nodules deemed inconclusive by fine needle aspirate (FNA). The study included 50 patients submitted

\section{Introduction}

\section{$\nabla$}

The telomerase reverse transcriptase (TERT) promoter mutations C228T and C250T have been found in several malignancies including melanoma, glioma, bladder, and thyroid cancer [1-4]. These mutations occur in 2 hot spot positions, located-124 and-146bp upstream from the ATG start site $(-124 \mathrm{G}>\mathrm{A}$ and $-146 \mathrm{G}>\mathrm{A}, \mathrm{C}>\mathrm{T}$ on the opposite strand) and confer enhanced TERT promoter activity putatively by generating a consensus binding site (GGAA) for ETS transcription factors within the TERT promoter region [2,3]. In thyroid cancers, TERT mutations have been correlated with aggressive tumor features. Moreover, they may be associated with BRAF or combined BRAF/RAS mutations [5,6]. On the basis of the available evidence, TERT mutations appear to influence the biological and clinical behavior of thyroid tumors, as well as patients survival and prognosis. Hence, TERT-mutated thyroid cancers may have a to CNB due to inconclusive FNA report. TERT mutational status was correlated with BRAF mutation, definitive histology, and post-operative TNM staging of the neoplasia. C228T mutation of the TERT promoter was reported in $10 \%$ of the papillary carcinomas (PTC) series. When compared with final histology, all cases harboring TERT mutation resulted as locally invasive PTCs. The prevalence of TERT mutated cases was $17.6 \%$ among locally advanced PTCs. TERT analysis on CNB allows the assessment of the pathological population on paraffin sections before DNA isolation, minimizing the risk of false negatives due to poor sampling that affects FNA, and gathering aggregate information about morphology and TERT mutational status. Data indicating a worse outcome of the tumor might be used to individualize treatment decision, surgical option, and follow-up design.

worse outcome, with a higher rate of disease recurrence and a higher disease-specific mortality [7]. TERT promoter mutations have been investigated in papillary (PTC), follicular (FTC), poorly differentiated (PDTC), and anaplastic (ATC) thyroid carcinomas with a prevalence of $7.5,17.1,29$, and $33 \%$, respectively [8]. Noteworthy, to date no TERT mutation has been reported in non-neoplastic thyroid tissue [1]. While TERT mutations have not been generally reported in thyroid adenomas, a single study described the presence of the C228T mutation in follicular adenomas, mainly the atypical subtype. Due to the potential development into FTC of this type of lesions, TERT promoter mutations could represent an early genetic event in thyroid follicular tumors that do not yet reveal malignant features on routine histopathological workup [9]. On the basis of these recent data, the assessment of the presence of TERT mutations could hold a main role in the clinical diagnosis and management of thyroid cancer patients. 
The micro-histological evaluation of samples obtained by core needle biopsy (CNB) has been proposed for a conclusive definition of thyroid nodules with inadequate or indeterminate cytology. CNB provides in a large part of these nodules a conclusive diagnosis, with minimal side effects and good tolerability for the patient [10-16]. Recently, the micro-histological specimens obtained by CNB were demonstrated to be an excellent material for molecular and immunohistochemical studies [10,17].

The aim of the present study is to investigate the potential use of CNB for the preoperative assessment of TERT mutational status, in order to reach a more accurate definition of malignancy and a more appropriate planning of surgical extension. The results obtained on CNB were compared with final histology on surgical specimens with regard to histological diagnosis and pathological staging.

\section{Patients and Methods}

$\nabla$

\section{Patients}

The series included 50 thyroid nodules, retrospectively selected among 187 patients who underwent CNB during the last 2 years at 2 institutions: Ospedale Israelitico, Rome, and Ospedale Regina Apostolorum, Albano Laziale, Italy. Thirty-one cases of thyroid cancer (30 PTC, 1 FTC), 9 of follicular adenoma and 10 of nodular hyperplasia that underwent surgery with final histology were included in the present study. All these lesions had been submitted to CNB due to an inconclusive FNA report of indeterminate (Thy 3/TIR3), or inadequate (Thy 1/TIR1) thyroid cytology [18-20]. At CNB 26 PTC, 5 follicular neoplasms, 11 follicular proliferation/indeterminate, and 8 benign hyperplasias were recorded. Informed consent was obtained from all patients. The 50 enrolled specimens were previously evaluated and submitted to manual dissection in order to obtain an amount of over $50 \%$ of lesional cells and in order to rule out the presence of inflammatory component for the correct interpretation of the study results.

\section{CNB and micro-histological examination}

Thyroid CNB procedure was performed under ultrasound guidance in an outpatient surgery unit as previously described $[15,17,21]$. Core samples were fixed in $10 \%$ buffered formalin immediately following the biopsy. Formalin-fixed tissue cores were automatically processed and embedded in paraffin. Then, $4 \mu \mathrm{m}$ sections were collected on positively charged slides and stained with hematoxylin-eosin for morphological evaluation. Microscopic diagnosis was reported as PTC when the typical features were present, as follicular hyperplasia when the micro-follicular pattern was combined with normo- and macrofollicular aspects and was seen next to non-neoplastic parenchyma, and as follicular neoplasm when micro-follicular pattern was monomorphic with crowed nuclei and separated from nonneoplastic parenchyma by thick fibrous septa (probably fibrous capsule). Follicular proliferation/indeterminate was reported when a follicular pattern was detected but the sample did not contain the limit with extra-nodular parenchyma.

\section{Final histology}

After surgery, thyroid explants were formalin-fixed and paraffin-embedded for routine histology. Thyroid tumors and lesions were classified according to the most recent criteria of the World Health Organization [22]. TNM staging was performed in agreement with AJCC $7^{\text {th }}$, edition [23].

\section{TERT mutational analysis}

TERT mutational analysis was performed by Sanger sequencing. Genomic DNA was isolated from formalin-fixed, paraffinembedded tissue samples. Five $\mu \mathrm{m}$ paraffin sections were dewaxed, hydrated and submitted for DNA extraction using the QIAamp DNA Mini Kit (Qiagen, Germany) after manual dissection of the pathological areas. About 40-50 ng of genomic DNA were used in the PCR. Sequencing of TERT promoter to detect the mutations C228T and C250T located at positions -124 and $-146 \mathrm{bp}$ upstream of the ATG (start codon) was carried out as recently reported [7]. The target region was amplified by polymerase chain reaction (PCR) using primers 5 '-AGTGGATTCGCGGGCACAGA-3' (forward) and 5'-CAGCGCTGCCTGAAACTC-3' (reverse), resulting in a PCR product of $235 \mathrm{bp}$, which contained the sites of C228T and C250T mutations (chr5: 1,295,228; chr5: 1,295,250, respectively; hg19) [7].

The amplification protocol consisted of an initial denaturation at $95^{\circ} \mathrm{C}$ for $3 \mathrm{~min}, 40$ cycles of denaturation at $95^{\circ} \mathrm{C}$ for $40 \mathrm{~s}$, annealing at $55^{\circ} \mathrm{C}$ for $40 \mathrm{~s}$, extension at $68^{\circ} \mathrm{C}$ for $1 \mathrm{~min}$, followed by a final extension at $68^{\circ} \mathrm{C}$ for $10 \mathrm{~min}$. Each reaction mixture contained $10 \mathrm{mmol} / \mathrm{l}$ Tris (pH 8.3), $200 \mu \mathrm{mol} / \mathrm{l}$ of each deoxynucleotide triphosphate (dNTP), $1.5 \mathrm{mmol} / \mathrm{l}$ magnesium chloride, $50 \mathrm{mmol} / \mathrm{l}$ potassium chloride, $10 \mathrm{pmol}$ of each primer, $50 \mathrm{ng}$ of genomic DNA, and $0.2 \mathrm{U}$ of Taq polymerase, in a final volume of $10 \mu \mathrm{l}$. A single major PCR product was confirmed by electrophoresing each PCR product on a $2.5 \%(\mathrm{w} / \mathrm{v})$ agarose gel. PCR products were subsequently sequenced using the above described forward primer and Big Dye terminator V 3.1 cycle sequencing reagents (Life Technologies) by PCR amplification (25 cycles of denaturation at $96^{\circ} \mathrm{C}$ for $10 \mathrm{~s}$, annealing at $50^{\circ} \mathrm{C}$ for $5 \mathrm{~s}$, and extension at $60^{\circ} \mathrm{C}$ for $4 \mathrm{~min}$ ). Each DNA sequence was read on an ABI-Prism 3100 automatic sequencer (Life Technologies). The generated sequences were analyzed using Geneious ver. 7.1.7 software (www.geneious.com).

When a mutation was identified by Big Dye sequencing using the sense primer, an independent PCR amplification/sequencing, both in forward and reverse directions, was performed to confirm the mutation.

\section{BRAF mutational analysis}

The analysis of BRAF mutational status was performed as previously described [17]. Briefly, $5 \mathrm{ml}$ of genomic DNA was amplified and sequenced using an Anti-EGFR Moab Response ${ }^{\circledR}$ (BRAF status) kit, (Diatech Pharmacogenetics Srl, Jesi, Italy) according to the manufacturer's instructions.

Real-time PCR was run on a Rotor-Gene ${ }^{\mathrm{TM}} 6000$ (Corbett, Sydney, Australia). After amplification, the presence of $P C R$ products was detected by melting analysis. For pyrosequencing analysis, single-stranded DNA templates were immobilized on streptavidin-coated Sepharose high-performance beads (GE Healthcare, Uppsala, Sweden) and then annealed to the sequencing primer using the PyroMark ${ }^{\mathrm{TM}}$ Q96 Vacuum Prep Workstation (Biotage AB, Qiagen). The primed single-stranded DNA templates were then transferred to the microtiter plate-based PSQ HS 96 (Biotage, Sweden), where real-time sequencing of the sequence surrounding codon 600 of BRAF was performed by using PyroMark ${ }^{\mathrm{TM}}$ Gold reagents (Qiagen) on a PyroMark ${ }^{\mathrm{TM}}$ Q96 ID instrument (Biotage, Sweden). A negative control and a wild-type control were run with each series of samples. Real-time curves and pyrograms were interpreted according to the kit instructions and PyroMark ID software (Qiagen) allowed determination of mutant allelic frequency according to relative peak height. 


\section{Data analysis}

TERT point mutation observed by Sanger was correlated with pyrosequencing analysis of BRAF, definitive histological diagnosis, and post-operative TNM staging of the neoplasia. For the positive TERT mutation cases, the mutational analysis was confirmed on final post-surgical histological samples to verify the reliability of TERT mutational status in CNB specimens. TERT mutational analysis was also performed on 5 definitive specimens randomly selected among PTC cases with CNB wild type for C228T.

\section{Results}

At final histology after surgery, all 26 PTC and 8 hyperplasias diagnosed at microhistology were confirmed; 5 follicular neoplasms resulted in 1 follicular carcinoma and 4 adenomas;

Table 1 Histological types, TNM staging, and BRAF/TERT mutational status recorded in 48 thyroid lesions.

\begin{tabular}{|c|c|c|c|}
\hline TERT status & Histologic type & TNM * & $\begin{array}{l}\text { BRAF mutated } \\
\text { cases }\end{array}$ \\
\hline \multirow{4}{*}{$\begin{array}{l}\text { TERT mutated } \\
(\mathrm{n}=3)\end{array}$} & \multirow[t]{4}{*}{ PTC $(n=3)$} & T4 N1b $(n=1)$ & 1 \\
\hline & & T3m N1b $(n=1)$ & 1 \\
\hline & & T3 N1a $(n=1)$ & 1 \\
\hline & & All & $3(100 \%)$ \\
\hline \multirow{15}{*}{$\begin{array}{l}\text { TERT wild type } \\
(n=45)\end{array}$} & \multirow[t]{12}{*}{ PTC $(n=27)$} & T3m N1a $(n=1)$ & 1 \\
\hline & & T3 N1b $(n=3)$ & 1 \\
\hline & & T3 N1a $(n=3)$ & 1 \\
\hline & & T3 N0 $(n=6)$ & 2 \\
\hline & & T3 Nx $(n=1)$ & 1 \\
\hline & & T1a N1a $(n=3)$ & - \\
\hline & & T2 No $(n=1)$ & - \\
\hline & & $\mathrm{T} 2 \mathrm{Nx}(\mathrm{n}=3)$ & 1 \\
\hline & & T1am N0 $(n=1)$ & 1 \\
\hline & & T1a N0 $(n=1)$ & - \\
\hline & & T1a Nx $(n=4)$ & - \\
\hline & & All & $8(29.6 \%)$ \\
\hline & $\operatorname{FTC}(n=1)$ & $\mathrm{T} 2 \mathrm{Nx}(\mathrm{n}=1)$ & - \\
\hline & FA $(n=8)$ & - & - \\
\hline & $\begin{array}{l}\text { Nodular hyperplasia } \\
(\mathrm{n}=9)\end{array}$ & - & - \\
\hline
\end{tabular}

regarding those 11 lesions assessed at CNB as uncertain/indeterminate, 4 PTC, 5 follicular adenomas, 2 nodular hyperplasias, were found. Two cases out of the indeterminate CNB did not allow adequate DNA extraction for the molecular analysis. As above, the collected DNA was adequate for molecular analysis in all but 2 of the 50 CNB samples (96\%). The 2 cases (1 adenoma and 1 nodular hyperplasia, $4 \%$ ) had insufficient quality of DNA due to extensive fragmentation and were therefore excluded from the study.

- Table 1 describes the results and the correlation between the presence of TERT mutation and the multifocality, TNM stage, and BRAF mutational status of the series of thyroid lesions under evaluation. C228T mutation of the TERT promoter was reported in 3 of 30 PTCs (10\%), while the only case of FC, the adenomas, and the hyperplastic nodules did not show TERT mutation and were classified as wild-type.

- Fig. 1 shows representative DNA sequence electropherograms of thyroid tissue samples with and without C228T mutation in the TERT promoter. All C228T mutated PTCs showed advanced TNM staging, with an incidence of $17.6 \%$ among the locally advanced (T3, T4) PTC series.

The BRAF mutational status was assessed in all 48 cases with sufficient DNA. Of these, 11 (22.9\%) were V600E mutated and the remaining 37 (77.1\%) were wild-type. In agreement with the literature [24], V600E mutation was restricted to PTCs (36.6\%). Among BRAF mutated cases the mutation rate at pyrosequencing ranged from 14.2 to $39.1 \%$. Of relevance, all TERT mutated PTCs showed concomitant BRAF mutation (० Table 1). 0 Fig. 2 shows the histology of one of the double mutated cases.

All cases with a C228T TERT mutation on CNB showed the same mutation on surgical specimens. The 5 cases of PTC with negative TERT analysis on CNB resulted in wild-type for C228T on the definitive histology.

\section{Discussion \\ $\nabla$}

Due to its high sensitivity, specificity and accuracy, thyroid FNA has been established as the main tool to identify malignant thyroid nodules [25]. Its main limitations are non-diagnostic and indeterminate (follicular) specimens, the latter accounting for about $15-20 \%$ of all results $[26,27]$. In these cases, the diagnosis of cancer cannot be reliably excluded on a morphological basis,

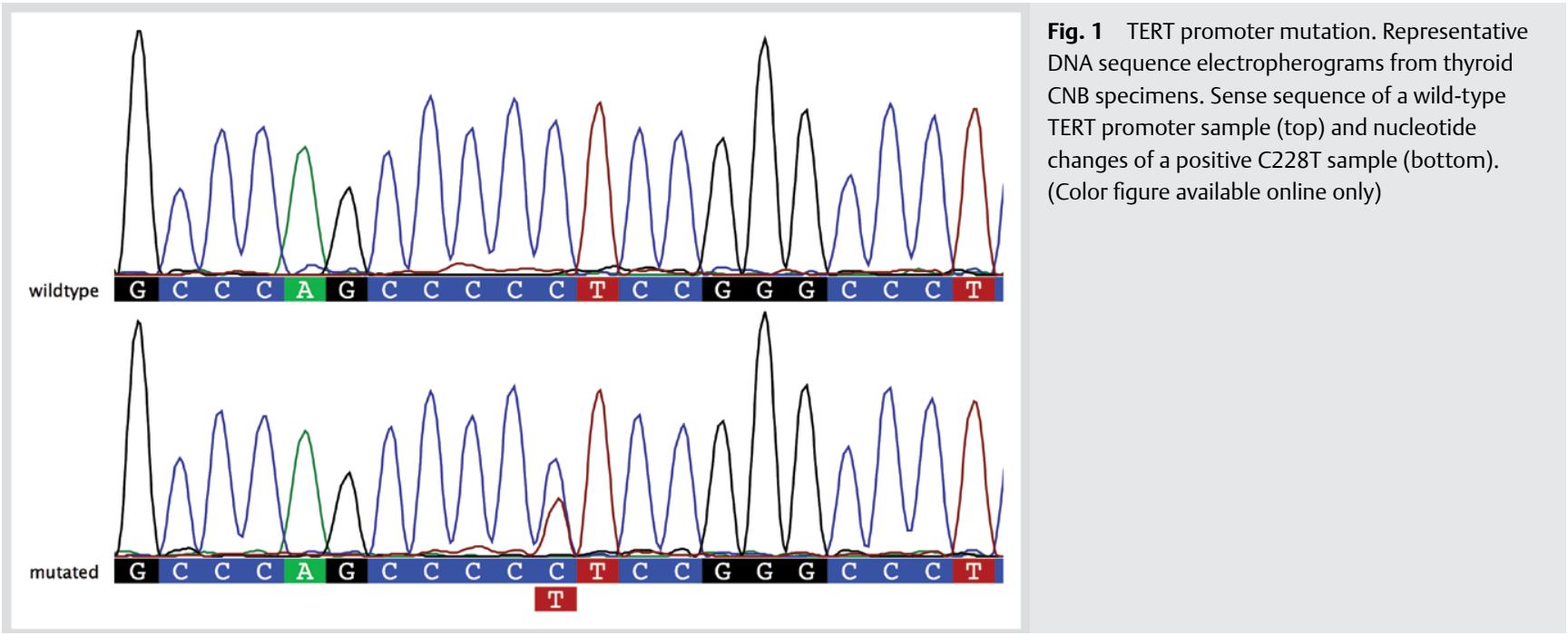




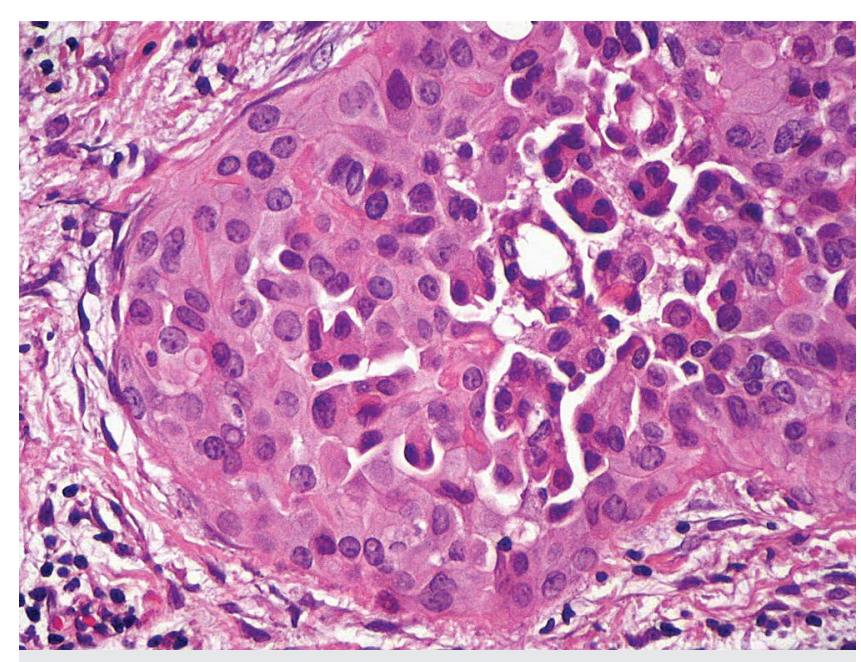

Fig. 2 Histological diagnosis. Papillary thyroid carcinoma harboring TERT and BRAF mutations. Fibrous stromal reaction is evident around neoplastic foci. $\mathrm{H} \& \mathrm{E}$ high power field. (Color figure available online only)

and the patients require surgery for a conclusive diagnosis. At final histology, the malignancy rate in these cytological categories results in about $25 \%$ [28]. In the area of indeterminate and inconclusive cytological diagnoses, several studies analyzing clinical, cytological, imaging, or molecular parameters as potential risk predictors have been reported, with controversial findings [29]. To date, however, a reliable diagnostic molecular marker that may be of use for both follicular and papillary thyroid carcinomas is still lacking. This represents a major drawback when the option between a conservative or surgical management of these patients is considered.

To overcome this limitation, during the last decade a flourishing number of research reports have identified novel molecular markers to better assess thyroid cancer aggressiveness, and their use has been proposed for clinical practice [30-32]. In particular, great relevance has been ascribed to the mutations of BRAF, RAS, RET/PTC, and PAX8/PPAR $\gamma$, which have been in some cases described as potential malignancy predictors [30-32]. The demonstration of somatic mutations in about two-thirds of PTCs (BRAF mutations and RET/PTC rearrangements) and of FTCs (RAS mutations and PAX8/PPARY rearrangements) has opened new perspectives for the classification and diagnosis of thyroid tumors. BRAFV600E represents the most extensively studied mutation in this diagnostic context. Unfortunately, the diagnostic effectiveness of the detection of BRAF mutation in reassessing inconclusive cytological cases is definitely low [30].

More recently, some studies have found evidence that patients with TERT-mutated tumors had a decreased survival if compared to TERT wild-type tumors. TERT mutations were reported as highly prevalent in advanced thyroid cancers, particularly in those harboring BRAF or RAS mutation [33], since the acquisition of a TERT promoter mutation may prolong the survival of BRAF or RAS driven clones and make possible the accumulation of additional genetic defects, leading to disease progression. Additionally, a significant association of TERT promoter mutations with distant metastasis and shorter disease-specific survival was found in FTCs and PTCs as a whole [34]. The identification of TERT mutations as a prognostic marker in differentiated thyroid carcinomas (DTC) may turn relevant for 2 reasons: i) only a small percentage of these carcinomas behave aggressively and may ultimately turn lethal, and ii) reliable prognostic indicators in this pathologic setting are up to now lacking [8].

The main limitation in the preoperative use of thyroid molecular markers relies on the low reliability of FNA specimens for these ancillary studies, so that current international guidelines do not recommend their routine use. In this setting, the ATA guideline states: "Many of these markers are available for commercial use in reference laboratories but have not yet been widely applied in clinical practice. It is likely that some combination of molecular markers will be used in the future to optimize management of patients with indeterminate cytology on FNA specimens. The use of molecular markers may be considered for patients with indeterminate cytology on FNA to help guide management" [35]. We propose CNB as a sample, which allows combination of morphology, immunohistochemistry, and molecular analysis. Very recently, a paper by Liu et al. [36] evaluated TERT status in 308 cytological FNA samples. They recorded a 7\% rate of TERT mutated cancers and no TERT mutations in benign lesions. However, a genetic confirmation in surgical samples was not performed. Then, the actual reliability of FNA samples to detect TERT mutated thyroid cancers is still not known.

Core needle biopsy has been described as a diagnostic tool in inconclusive cytological diagnosis $[10,15,37]$, and the microhistological evaluation of CNB samples has been proposed as a complementary diagnostic tool for thyroid nodules with inconclusive FNA reports. By CNB, a large percentage of nodules that are read as indeterminate or inadequate at FNA examination may be reassessed as diagnostic. The semiautomated CNB needles used are of small caliber (20 to 22 gauge), allowing full access to both large and small thyroid nodules with few complications and high patient tolerability [16]. The device's cost is slightly higher than those of FNA but it is the same for all biopsy practices, also of others organs. Moreover, due to the availability of multiple paraffin sections, the core specimen is perfectly suitable for ancillary studies including molecular and immunochemical markers, and therefore improves diagnostic and prognostic evaluation.

To our knowledge, there are no reports on the clinical use of TERT analysis for the preoperative evaluation of patients with thyroid nodular disease on CNB specimens. Noteworthy, the inadequacy rate for molecular analysis in our study on CNB samples was only $4 \%$, much lower than the reported adequacy on FNA specimens, about $8 \%$ in specialized centers [37]. Of importance, we performed the microscopic dissection of core sections to obtain DNA isolation from samples with at least $50 \%$ of pathological cells. These enriched samples avoid problems due to the relatively low sensitivity of the Sanger method. This possibility is one of the additional values of the CNB vs. FNA methodology. To support our affirmation we performed TERT mutational analysis on 5 definitive specimens randomly selected among PTC cases with CNB wild type for C228T, and all of them confirmed the wild type status. For the positive TERT mutation cases on $\mathrm{CNB}$, moreover, the mutational status was confirmed on final post-surgical histological samples.

When compared with final histological diagnosis and staging, all our cases harboring TERT mutation (10\% of the PTC series) resulted as locally invasive PTC with multiple lymph-nodes metastasis and, in one patient, with lung metastasis. These results are in agreement with the high prevalence of TERT mutation reported in the advanced form of the disease [33]. In our series, the prevalence of TERT mutated cases is $17.6 \%$ among 
locally advanced PTCs. On the other hand, no TERT mutation was found in follicular adenomas or hyperplasia, confirming the previous data $[7,8]$ reporting a mutation that is restricted to malignant lesions. In agreement with a recent publication [35], a positive TERT promoter mutation test not only definitively diagnoses a thyroid nodule as cancer, but also preoperatively identifies a cancer with aggressive potential. Moreover, our results confirm the association of TERT mutation with BRAF V600E mutation, highlighting the coexistence of activation of BRAF and of TERT genes previously reported in melanoma [2] and thyroid carcinoma $[1,5,6]$.

In consideration of the poor response to radioiodine treatment demonstrated by DTCs with TERT mutation, this information could be particularly relevant during staging of the patients, according to the current trend to appropriately limit the number of patients submitted to radioiodine ablation.

A recent publication gives evidence of a diagnostic and prognostic role of TERT promoter mutations in thyroid fine needle biopsy (FNA) demonstrating the value of this novel molecular testing in the diagnosis and risk stratification of thyroid nodule [36]. The present study demonstrates the feasibility of TERT promoter mutational analysis on thyroid core needle biopsies: this methods allows the assessment of pathological population on paraffin sections before DNA isolation avoiding the risk of TERT false negative due to inadequate or poor sampling by FNA.

The possibility to reliably identify TERT mutations on thin core biopsy samples enables the extension of the proposed methodology to solid tumors in different anatomical sites usually sampled by CNB and in which TERT has been identified as negative prognostic marker. The most important added value of the present study is the demonstration of viability of TERT mutational analysis on thyroid core biopsy during the initial evaluation of patients with thyroid nodule, providing aggregate information about morphology and TERT mutational status. Targeting molecular markers for risk stratification and surgical indication, the inclusion of TERT within the traditional mutational panel [38], characterized by a nearly $63 \%$ sensitivity, could further increase the diagnostic accuracy of preoperative molecular analysis in thyroid nodular diseases. This approach moreover may integrate other tests aimed to best predict malignancy in thyroid nodules [39-41].

The information indicating a worse outcome of the tumor, may be used to individualize treatment decision, surgical option, and follow-up design. The major advantage of TERT mutational analysis on thyroid CNB when compared with FNA cytology is the more constant availability and adequacy of cellular material for a complete molecular analysis.

\section{Conflict of Interest}

The authors declare no conflict of interest.

\footnotetext{
Affiliations

${ }^{1}$ Pathology Unit, Campus Bio-Medico University Hospital, Rome, Italy

2 Section of Endocrinology and Diabetology, Ospedale Israelitico, Rome, Italy

${ }^{3}$ Section of Pathology, Ospedale Israelitico, Rome, Italy

${ }^{4}$ Section of Pathology, Ospedale Regina Apostolorum, Albano Laziale, Rome, Italy

${ }^{5}$ Tissue Engineering Unit, Campus Bio-Medico University, Rome, Italy

${ }^{6}$ Section of Endocrinology, Ospedale Regina Apostolorum, Albano Laziale,

Rome, Italy

${ }^{7}$ Institute of Human Anatomy and Cell Biology, Sacro Cuore Catholic

University Hospital, Rome, Italy
}

\section{References}

1 Vinagre J, Almeida A, Pópulo H, Batista R, Lyra J, Pinto V, Coelho $R$, Celestino R, Prazeres H, Lima L, Melo M, da Rocha AG, Preto A, Castro P, Castro L, Pardal F, Lopes JM, Santos LL, Reis RM, Cameselle-Teijeiro $J$, Sobrinho-Simões M, Lima J, Máximo V, Soares P. Frequency of TERT promoter mutations in human cancers. Nat Commun 2013; 4: 2185

2 Horn S, Figl A, Rachakonda PS, Fischer C, Sucker A, Gast A, Kadel S, Moll I, Nagore E, Hemminki K, Schadendorf D, Kumar R. TERT promoter mutations in familial and sporadic melanoma. Science 2013; 339: 959-961

3 Huang FW, Hodis E, Xu MJ, Kryukov GV, Chin L, Garraway LA. Highly recurrent TERT promoter mutations in human melanoma. Science 2013; 339: 957-959

4 Killela PJ, Reitman ZJ, Jiao Y, Bettegowda C, Agrawal N, Diaz LA, Friedman AH, Friedman H, Gallia GL, Giovanella BC, Grollman AP, He TC, He $Y$, Hruban RH, Jallo GI, Mandahl N, Meeker AK, Mertens F, Netto GJ, Rasheed BA, Riggins GJ, Rosenquist TA, Schiffman M, Shih IM, Theodorescu $D$, Torbenson MS, Velculescu VE, Wang TL, Wentzensen N, Wood $L D$, Zhang M, McLendon RE, Bigner DD, Kinzler KW, Vogelstein B, Papadopoulos $N$, Yan $H$. TERT promoter mutations occur frequently in gliomas and a subset of tumors derived from cells with low rates of self-renewal. Proc Natl Acad Sci U S A 2013; 110: 6021-6026

5 Xing M, Liu R, Liu X, Murugan AK, Zhu G, Zeiger MA, Pai S, Bishop J. BRAF V600E and TERT Promoter Mutations Cooperatively Identify the Most Aggressive Papillary Thyroid Cancer With Highest Recurrence. J Clin Oncol 2014; 32: 2718-2726

6 Liu X, Qu S, Liu R, Sheng C, Shi X, Zhu G, Murugan AK, Guan H, Yu H, Wang $Y$, Sun $H$, Shan $Z$, Teng $W$, Xing $M$. TERT promoter mutations and their association with BRAF V600E mutation and aggressive clinicopathological characteristics of thyroid cancer. J Clin Endocrinol Metab 2014; 99: E1130-E1136

7 Liu X, Bishop J, Shan Y, Pai S, Liu D, Murugan AK, Sun H, El-Naggar $A K$, Xing $M$. Highly prevalent TERT promoter mutations in aggressive thyroid cancers. Endocr Relat Cancer 2013; 20: 603-610

8 Melo M, da Rocha AG, Vinagre J, Batista R, Peixoto J, Tavares C, Celestino $R$, Almeida A, Salgado C, Eloy C, Castro P, Prazeres H, Lima J, Amaro T, Lobo C, Martins MJ, Moura M, Cavaco B, Leite V, Cameselle-Teijeiro JM, Carrilho F, Carvalheiro M, Máximo V, Sobrinho-Simões M, Soares $P$. TERT promoter mutations are a major indicator of poor outcome in differentiated thyroid carcinomas. J Clin Endocrinol Metab 2014; 99: E754-E765

9 Wang N, Liu T, Sofiadis A, Juhlin CC, Zedenius J, Höög A, Larsson C, Xu $D$. TERT promoter mutation as an early genetic event activating telomerase in follicular thyroid adenoma (FTA) and atypical FTA. Cancer 2014; 120: 2965-2979

10 Park KT, Ahn SH, Mo JH, Park YJ, Park dJ, Choi SI, Park SY. Role of core needle biopsy and ultrasonographic finding in management of indeterminate thyroid nodules. Head Neck 2011; 33: 160-165

11 Sung JY, Na DG, Kim KS, Yoo H, Lee H, Kim JH, Baek JH. Diagnostic accuracy of fine-needle aspiration versus core-needle biopsy for the diagnosis of thyroid malignancy in a clinical cohort. Eur Radiol 2012; 22: $1564-1572$

12 Na DG, Kim JH, Sung JY, Baek JH, Jung KC, Lee H, Yoo H. Core-needle biopsy is more useful than repeat fine-needle aspiration in thyroid nodules read as nondiagnostic or atypia of undetermined significance by the Bethesda system for reporting thyroid cytopathology. Thyroid 2012; 22: 468-475

13 Renshaw AA, Pinnar N. Comparison of thyroid fine-needle aspiration and core needle biopsy. Am J Clin Pathol 2007; 128: 370-374

14 Samir AE, Vij A, Seale MK, Desai G, Halpern E, Faquin WC, Parangi S, Hahn PF, Daniels GH. Ultrasound-guided percutaneous thyroid nodule core biopsy: clinical utility in patients with prior nondiagnostic fineneedle aspirate. Thyroid 2012; 22: 461-467

15 Nasrollah N, Trimboli P, Guidobaldi L, Cicciarella Modica DD, Ventura C, Ramacciato G, Taccogna S, Romanelli F, Valabrega S, Crescenzi A. Thin core biopsy should help to discriminate thyroid nodules cytologically classified as indeterminate. A new sampling technique. Endocrine 2013; 43: 659-665

16 Nasrollah N, Trimboli P, Rossi F, Amendola S, Guidobaldi L, Ventura $C$, Maglio R, Nigri G, Romanelli F, Valabrega S, Crescenzi A. Patient's comfort with and tolerability of thyroid core needle biopsy. Endocrine 2014; 45: 79-83

17 Crescenzi A, Guidobaldi L, Nasrollah N, Taccogna S, Cicciarella Modica $D D$, Turrini L, Nigri G, Romanelli F, Valabrega S, Giovanella L, Onetti Muda A, Trimboli P. Immunohistochemistry for BRAF(V600E) antibody VE1 performed in core needle biopsy samples identifies mutated papillary thyroid cancers. Horm Metab Res 2014; 46: 370-374 
18 The Bethesda System for Reporting Thyroid Cytopathology: Definitions, Criteria and Explanatory Notes. New York: Springer Science + Business Media, 2010

19 Kocjan G, Cochand-Priollet B, de Agustin PP, Bourgain C, Chandra A, Daneshbod Y, Deery A, Duskova J, Ersoz C, Fadda G, Fassina A, Firat P, Jimenez-Ayala B, Karakitsos $P$, Koperek O, Matesa N, Poller D, Thienpont $L$, Ryska A, Schenck $U$, Sauer T, Schmitt F, Tani E, Toivonen T, Tötsch M, Troncone G, Vass L, Vielh P. Diagnostic terminology for reporting thyroid fine needle aspiration cytology: European Federation of Cytology Societies thyroid working party symposium, Lisbon 2009. Cytopathology 2010; 21: 86-92

20 Nardi F, Basolo F, Crescenzi A, Fadda G, Frasoldati A, Orlandi F, Palombini L, Papini E, Zini M, Pontecorvi A, Vitti P. Italian consensus for the classification and reporting of thyroid cytology. J Endocrinol Invest 2014; 37: 593-599

21 Trimboli P, Nasrollah N, Guidobaldi L, Taccogna S, Cicciarella Modica DD, Amendola S, Romanelli F, Lenzi A, Nigri G, Centanni M, Giovanella L, Valabrega S, Crescenzi A. The use of core needle biopsy as first-line in diagnosis of thyroid nodules reduces false negative and inconclusive data reported by fine-needle aspiration. World J Surg Oncol 2014; 12: 61

22 Hedinger C, Williams ED, Sobin LH. Histological typing of thyroid tumoursWorld Health Organization International histological classification of tumours. Berlin: Springer-Verlag, 2014

23 AJCC Cancer Staging Manual. $7^{\text {th }}$ Edition, Berlin: Springer, 2010

24 Elisei $R$, Viola D, Torregrossa L, Giannini R, Romei C, Ugolini C, Molinaro E, Agate L, Biagini A, Lupi C, Valerio L, Materazzi G, Miccoli P, Piaggi P, Pinchera A, Vitti P, Basolo F. The BRAF(V600E) mutation is an independent, poor prognostic factor for the outcome of patients with low-risk intrathyroid papillary thyroid carcinoma: single-institution results from a large cohort study. J Clin Endocrinol Metab 2012; 97 : 4390-4398

25 Cibas ES, Ali SZ.Conference NTFSotS. The Bethesda System For Reporting Thyroid Cytopathology. Am J Clin Pathol 2009; 132: 658-665

$26 \mathrm{Wu} \mathrm{HH}$, Jones JN, Osman J. Fine-needle aspiration cytology of the thyroid: ten years experience in a community teaching hospital. Diagn Cytopathol 2006; 34: 93-96

27 Gharib H, Goellner JR. Fine-needle aspiration biopsy of thyroid nodules. Endocr Pract 1995; 1: 410-417

28 Rago T, Fiore E, Scutari M, Santini F, Di Coscio G, Romani R, Piaggi P, Ugolini C, Basolo F, Miccoli P, Pinchera A, Vitti P. Male sex, single nodularity, and young age are associated with the risk of finding a papillary thyroid cancer on fine-needle aspiration cytology in a large series of patients with nodular thyroid disease. Eur J Endocrinol 2010; 162: 763-770

29 Gul K, Ersoy R, Dirikoc A, Korukluoglu B, Ersoy PE, Aydin R, Ugras SN, Belenli OK, Cakir B. Ultrasonographic evaluation of thyroid nodules: comparison of ultrasonographic, cytological, and histopathological findings. Endocrine 2009; 36: 464-472
30 Eszlinger M, Paschke R. Molecular fine-needle aspiration biopsy diagnosis of thyroid nodules by tumor specific mutations and gene expression patterns. Mol Cell Endocrinol 2010; 322: 29-37

31 Nikiforova MN, Nikiforov YE. Molecular diagnostics and predictors in thyroid cancer. Thyroid 2009; 19: 1351-1361

32 Couto JP, Prazeres H, Castro P, Lima J, Máximo V, Soares $P$, SobrinhoSimões M. How molecular pathology is changing and will change the therapeutics of patients with follicular cell-derived thyroid cancer. J Clin Pathol 2009; 62: 414-421

33 Landa I, Ganly I, Chan TA, Mitsutake N, Matsuse M, Ibrahimpasic T, Ghossein RA, Fagin JA. Frequent somatic TERT promoter mutations in thyroid cancer: higher prevalence in advanced forms of the disease. J Clin Endocrinol Metab 2013; 98: E1562-E1566

34 Liu T, Wang N, Cao J, Sofiadis A, Dinets A, Zedenius J, Larsson C, Xu $D$. The age- and shorter telomere-dependent TERT promoter mutation in follicular thyroid cell-derived carcinomas. Oncogene 2014; 33: 4978-4984

35 Cooper DS, Doherty GM, Haugen BR, Kloos RT, Lee SL, Mandel SJ, Mazzaferri EL, McIver B, Pacini F, Schlumberger M, Sherman SI, Steward DL, Tuttle RM. Thyroid 2009; 19: 1167-1214

36 Liu R, Xing $M$. Diagnostic and prognostic TERT promoter mutations in thyroid fine needle biopsy. Endocr Relat Cancer 2014; 21: 825-830

37 Harvey JN, Parker D, De P, Shrimali RK, Otter M. Sonographically guided core biopsy in the assessment of thyroid nodules. J Clin Ultrasound 2005; 33: 57-62

38 Nikiforov YE, Ohori NP, Hodak SP, Carty SE, LeBeau SO, Ferris RL, Yip L, Seethala RR, Tublin ME, Stang MT, Coyne C, Johnson JT, Stewart AF, Nikiforova $M N$. Impact of mutational testing on the diagnosis and management of patients with cytologically indeterminate thyroid nodules: a prospective analysis of 1056 FNA samples. J Clin Endocrinol Metab 2011; 96: 3390-3397

39 Stokowy T, Wojtaś B, Fujarewicz K, Jarząb B, Eszlinger M, Paschke R. miRNAs with the potential to distinguish follicular thyroid carcinomas from benign follicular thyroid tumors: results of a meta-analysis. Horm Metab Res 2014; 46: 171-180

40 Trimboli P, Treglia G, Giovanella L. Preoperative Measurement of Serum Thyroglobulin to Predict Malignancy in Thyroid Nodules: A Systematic Review. Horm Metab Res 2015; 47: 247-252

41 Rosario PW, Penna GC, Calsolari MR. Predictive factors of malignancy in thyroid nodules with repeatedly nondiagnostic cytology (Bethesda category I): value of ultrasonography. Horm Metab Res 2014; 46: 294-298 